Dhlamini, J. P. \& Molaodi, V. T. Cross-fertilization in Teaching and Learning between Institutions after COVID-19 Shutdown: A Collaborative Effort

\title{
Cross-fertilization in Teaching and Learning between Institutions after COVID-19 Shutdown: A Collaborative Effort
}

\author{
Joyce Phikisile Dhlamini ${ }^{1} \&$ Vivian Thuso Molaodi ${ }^{* 1}$ \\ *Corresponding Author: \\ 1. North-West University, South Africa \\ Received : 2021-06-18 \\ Revised : 2021-08-20 \\ Accepted : 2021-09-15
}

How to cite this paper: Dhlamini, J. P. \& Molaodi, V. T. (2021). Cross-fertilization in Teaching and Learning between Institutions after COVID19 Shutdown: A Collaborative Effort. Research in Social Sciences and Technology, 6(3), 135-145. https://doi.org/10.46303/ressat.2021.34

This is an Open Access article distributed under the terms of the Creative Commons Attribution 4.0 International license (https://creativecommons.org/licenses/by/4.0/).

\begin{abstract}
Research reported in this article investigated the effectiveness of collaborative effort between schools to bridge the existing gaps that erupted during the outbreak of COVID-19. There are gaps in teaching and learning within the previously privileged institutions and the marginalised institutions in South Africa. Such gaps might have a negative impact on how teaching and learning are conducted. The purpose of this article was to investigate the creative and constructive ways of managing the anxiety related to socio-economic impacts in schools, amongst which were the introduction of online teaching and learning technologies, new methodologies and contents. This article is underpinned by the concepts of the establishment of advantageous strategies for collaboration, knowledge sharing and knowledge transfer. Qualitative document analysis has been adopted as a methodology to collect information for this study. The outbreak of COVID-19 has evoked inequalities amongst the communities. However, the re-opening of schools exacerbated multiple challenges. While teaching and learning is the centre of the education project in South Africa, which the country has to adapt to, most institutions were faced with a number of challenges. This study's major finding revealed that collaboration is synergistic and can bring out the best contribution that might currently perceive partnership within the school system. This article recommends ways of bridging the gap between schools through developing partnerships between institutions through cross-fertilisation.
\end{abstract}

Keywords: Bridging gaps, collaboration, knowledge transfer, knowledge sharing, inequalities. 
Dhlamini, J. P. \& Molaodi, V. T. Cross-fertilization in Teaching and Learning between Institutions after COVID-19 Shutdown: A Collaborative Effort

\section{Introduction}

Collaboration is not a simple and easy practice for people to engage in. It requires joint effort and envisions the world as interdependent and allows for participation in society in a cooperative fashion. Collaboration among various educational agencies has been a key concept promoted in educational reform movements (Kezar \& Lester, 2009). Educational institutions could envisage a cohesive collaboration that would enable partnership between the schools for a common goal. The hope is that collaboration will be synergistic and bring out the best results within the participants. Schools that do not have enough resources to cope with the demands of e-learning and those who may currently have resources might perceive resources as a sharing contradiction instead of collaboration.

This collaboration involves developing partnership and long-term coherence relationships between schools to tap on the strength of each entity. It also involves a refined plan of delivery, effective development process, efficient communication, accountability and evaluation of teaching-learning programs. There has been significant evidence that when the Department of Education, School Districts, schools in under-privileged communities pool their ideas, energies, and resources into a collaborative effort, the processes generated are not only richer in content but sounder in design (Heath \& Johnson-Taylor, 2006).

A closer relationship between secondary schools is precisely important. Such collaboration should feature involvement and agreement among all education personnel who are prepared to focus on projects that engage an active collaboration between schools (Bernshausen \& McMahan, 2011). Although collaboration may seem complicated, Kezar and Lester (2009) argue that collaboration is the most natural and the easiest practice for people to engage in and envisions the world as interdependent and allows for participation in society in a cooperative fashion. Therefore, collaboration among various educational agencies has been a key concept promoted in educational reform movements. The hope is that collaboration will be synergistic and bring out the best in participating contributors, that is, the schools that currently perceive contradiction instead of collaboration (Bernshausen \& McMahan, 2011).

\section{Problem Statement}

Research conducted by the University of Wits has proven that their first-year students struggle to cope with university education and curriculum (Habib, 2016). The research further discovered that even those students who obtained distinctions in their matric results are not coping in institutions of higher learning $(\mathrm{IHL})$. Some students are getting an average of only 50 per cent in their university modules. This proves that there is a lack of quality education in teaching and learning in some secondary schools, hence a need for collaboration as cited. (Habib, 2016).

Some schools are situated in rural areas and in some townships that hardly have electricity in the area. Such schools do not even have the necessary teaching and learning support materials (TLSM) such as laboratories, libraries, computer centres, internet, to name a few. On the other hand, some schools have the equipment and resources that can assist learners to be introduced to the modern Information and Communication Technology (ICT) they need for their research work in their school subjects. Apparently, such dispensations provide unequal access to 
Dhlamini, J. P. \& Molaodi, V. T. Cross-fertilization in Teaching and Learning between Institutions after COVID-19 Shutdown: A Collaborative Effort

technology, giving some students advantages over others (Williams et al., 2021). Thus, ICT in schools encourage teachers and learners to join online platforms that allow for connectivity and engagement among users (Waters \& Hensley, 2020). The majority of learners who "pass" matric are not admitted into the university due to the admission requirements of institutions of higher learning. Universities have specific expectations of what students will learn through each teaching programme offered by that university. It is not surprising that these expectations are not fully met due to a lack of collaboration between the school sites to assist each other (Heath, 2005; Heath \& Johnson-Taylor, 2006). Such collaboration between school advance communication and prepares learners to cope with university work when they embark on further studies. Equipping learners would answer the outcry as it was stated that "first-year university students are not coping with their studies" when they embark for tertiary institutions (Habib, 2014). It is thus imperative for schools to work together collaboratively in order to share resources.

\section{Aim of the Research}

The major aim of this research project was to establish effective collaboration and partnership conversations between secondary schools. The focus was on advantageous strategies of collaboration, knowledge-transfer and knowledge sharing among secondary schools as an effective tool for working together. When learners pass their final grade at high school, they aim to further their studies through the institutions of higher learning. Therefore, the effective collaboration within secondary schools would benefit learners from sharing knowledge and resources and be exposed to the expectations of the institutions of higher learning, including the universities and the further education and training colleges (FET), when learners progress after matric. However, collaboration aims at not benefiting the learners only but teachers and the entire school population (Heath \& Johnson-Taylor, 2006).

\section{Methodology}

The research method employed in this research to collect information was qualitative document analysis. In the document analysis, the authors analysed documents of the Department of Education, academic research reports, strategic plans and reports such as the NEEDU (2012) report, the Constitution of the Republic of South Africa (RSA, 1996), (DoE, 2010) and South African legislation. Policies constitute the guidelines and draft policies - academic literature such as scholarly articles on collaboration. The national strategic plans and progress reports written by state departments were also analysed.

\section{Conceptual Framework}

Conceptual framework used in this research includes the concepts of strategies for the collaboration known as advantageous strategies for collaboration (ASC) concept of knowledge sharing (KS) and the concept of knowledge transfer (KT). Wu et al. (2004), Daniel et al. (2002) and Dyer and Powell (2001) were engaged in this article. Wu et al. (2004) ASC outline that in order to achieve successful collaboration, effective strategies are important. In this study, these strategies consisted of the infrastructure in the school. They further elucidate that collaborative advantage is the ability to form effective and rewarding partnerships with other institutions for mutual benefit that involves collaboration and creating new value together rather than being 
Dhlamini, J. P. \& Molaodi, V. T. Cross-fertilization in Teaching and Learning between Institutions after COVID-19 Shutdown: A Collaborative Effort

a simple exchange or transaction. Infrastructure in the school refers to the availability of teaching and learning resources. Is there any access to ICT that the school is providing to the learners? Does the school have computers and other teaching and learning resources? Is there any collaboration with the other schools in the neighbourhood for assistance? The relationships that the school forms with other schools are imperative. Such relationships became vital as Departments of Education implemented new teaching methods designed to preserve the sense of community during distance learning (William et al., 2021).

ASC strategy is important because the institutions involved in this collaboration share the available resources. It is evident that most township schools do not have enough (TLSM) to enable learners to learn successfully. However, through collaboration, the institutions could share the resources to the advantage of the learners. This collaboration includes the functioning of the school. The process of collaboration includes curriculum management to delivery and learner engagement which is the main focus of successful teaching and learning. The importance of ASC is to create learning activities that are important and necessary for learning (Wu et al., 2004). It also prepares learners to be part of a team and work collaboratively with other learners.

The second concept is knowledge sharing (KS) by Dyer and Powell (2001), which focuses on sharing the resources available. The schools should participate in sharing the knowledge that they have with the schools that need assistance. It is important to develop partnerships with other institutions in order to share resources, thus sharing the knowledge. This is a process where knowledge is shared as an activity through which knowledge is exchanged among learners and educators in schools. By knowledge sharing, schools can exchange skills and expertise among each other. Schools must be assisted in sharing their resources with other schools, and they should also develop a system of networking with other tertiary institutions as well. This is a crucial strategy as it involves the use of Information and Communications Technology (ICT).

In the third concept, which is knowledge transfer (KT), Daniel et al. (2002) intimate that any organisation that can enhance their research capacity would increase knowledge and bring development to schools. This project assisted the university to enhance its research capacity thus sharing and advancing the performance of the three secondary schools in Heidelberg. The advancement of these secondary schools was brought about through by the effective strategies of collaboration between these institutions and the sharing of knowledge. The project monitored collaboration within the institutions and the staff (Hutchings \& Michailova 2003; Law \& Ngai, 2008).

\section{Literature Review}

\section{Working relationships between institutions}

The establishment of a working relationship between schools was a major goal of this study. Effective collaboration between secondary schools has been a challenging effort. Such collaborations have become particularly essential presently due to various changes in the school curriculum by the Department of Basic Education (DoE). The DoE established the National Curriculum Statement (NCS), which lowered the pass requirement for exiting grade 
Dhlamini, J. P. \& Molaodi, V. T. Cross-fertilization in Teaching and Learning between Institutions after COVID-19 Shutdown: A Collaborative Effort

12 learners to tertiary education. When such learners receive their results at the end of their year of study, indicating that they have passed, the IHL does not admit them due to the low points that they have earned for their secondary school subjects (Pinnock \& Hodgkin, 2010).

According to the National Education Evaluation \& Development Unit (NEEDU) report, there has been an agreement between the Minister of Basic Education and the President of South Africa to improve the matric pass rate in the country (NEEDU, 2012). However, reports show that results are not meeting the targets agreed upon (DoE, 2012). As a result, more school leavers find themselves excluded from further studies in tertiary institutions.

Collaboration enables both schools to handle different issues related to student objectives and future careers. Heath (2005) asserts that a superficial collaborative plan is likely to face a cultural clash and would have little chance to succeed. On the other hand, a well-planned activity, designed jointly by members of both institutions that consider the academic parameters of each institution has much a higher chance of succeeding. That collaboration helps participants to reflect on values, develop a shared vision and a sense of purpose around why collaboration is a good idea (Kezar \& Lester, 2009). For instance, Rismark and Solvberg (2011) argue that knowledge sharing as a key to professional learning should be organisationally supported. In addition, Akinyemi et al. (2019) report that teachers should collaborate and mutually engage in learning activities in communities of practice in high schools to enhance their professional development.

The research reported in this article investigated the effectiveness of collaborative effort between schools and recommended how to engage in this collaboration. In addition, it investigated the ways of bridging the gap between schools with sufficient resources and those who lack resources, with the aim of achieving internalisation and globalisation through developing partnerships between institutions through cross-fertilisation.

Literature has shown that there is a disparity in the way schools are funded (Department of Basic Education, 2016; du Plessis, 2020). One of the objectives is to arrive at recommendations that could be implemented by both quintiles 1 and 5 schools to prepare learners collaboratively for further education and training. Most schools categorised under quintile 1 are those schools in the rural areas, villages and townships. Parents in such school are mostly unemployed and hit by poverty. On the other hand, quintile 5 schools are mostly found in urban areas where parents are working and can afford to support the needs of the school.

\section{Why collaboration between schools?}

This is a significant effort to develop collaboration between schools through a project based on participation. The collaboration could be initiated to facilitate a project that sought to promote integration between secondary schools. Close collaboration between schools is an important piece towards the continuous improvement of learner performance and introduction of learners towards the programme, which might be useful at the universities (Walkington \& Seguin 2020). When educators from various schools and school principals are actively involved in determining the curriculum needs and improving on what is taught in the classroom including, lesson preparation, content knowledge, and instructional skills, teaching and learning will improve in schools. Heath (2005), Heath and Johnson-Taylor (2006) and Dyer and Powell (2001) 
Dhlamini, J. P. \& Molaodi, V. T. Cross-fertilization in Teaching and Learning between Institutions after COVID-19 Shutdown: A Collaborative Effort

suggest the most helpful aspects of school-to-school collaboration as that of sharing resources, including:

- Sharing expertise

- Conducting action research

- Service on school and university program improvement committees

- Making joint presentations at conferences.

Since 2005, the Outcomes-based Education (OBE) approach to the curriculum was introduced in South Africa. That brought about uncertainties among the teachers. In 2005, the National Curriculum Statement (NCS) was introduced and in 2008, the Revised National Curriculum Statement (RNCS) replaced its antecedent. Since 2010, a new curriculum known as Curriculum Assessment Policy Statement (CAPS) was introduced (DoE, 2010; Pinnock, 2011). All these changes in the curriculum leave the teachers and the learners in confusion as they attempt to adjust to all these changes, which eventually become challenges. The pass requirements of learners have been lowered to 30 per cent. When learners receive their results at the end of their matric year that they have passed, they ironically do not get admitted at the university. The major problem is the low standard and the parlous quality of learning that learners receive at the secondary school level (DoE, 1997; DoE, 2004; DoE, 2010).

Collaborations have become particularly essential recently due to the significant change in the demographics of post-secondary students. The outbreak of COVD-19 has brought many challenges in the education system. Such challenges are escalating due to societal differences, in addition to poverty. Presently, there has been a change in students' nature and career objectives, which have led to a high number of non-traditional students. However, the use of technology in IHL leaves out some students from underprivileged communities. Hence a stronger partnership and closer relationship between secondary schools are critical to the success and possible cross-fertilisation of institutions (Nage-Sibande \& van Vollenhoven, 2012). In taking on new ideas for collaboration between two different institutions, several factors need to be taken into account. One of the major factors is that IHL and secondary schools have different missions, and they deal with very different issues related to student objectives, educational goals. In addition, some schools are faced with budget issues (Kezar \& Lester, 2009).

\section{Involvement of the school management teams}

It is essential for a School Management Team (SMT) to change their attitude towards effective school management as they are expected to perform most of the managerial roles in the school and in support of any project which might bring change in improving the results of the school. They could even further request more information on programmes that would enhance their roles as managers in the school, by engaging themselves in the management of projects to bridge existing the gaps of "school community" in relation to the other "school community" so that schools can work collaboratively. They could also develop confidence in performing their duties and, most importantly, nurtured a positive attitude. The harmony prevails in the schools by implementing the advantageous strategies for collaboration, knowledge sharing, and knowledge transfer (Wu et al., 2004). Schools benefit from collaboration and continuously get involved in projects that are helpful to them as they could learn from sharing with other schools. 
Dhlamini, J. P. \& Molaodi, V. T. Cross-fertilization in Teaching and Learning between Institutions after COVID-19 Shutdown: A Collaborative Effort

There should be cohesion in the form of collaboration between the secondary schools to improve the performance of learners. The advantage of this collaboration is the implementation of the curriculum which is prescribed to all schools operating under the Department of Education in South Africa and ensuring that lesson plans used in schools are in accordance with the Curriculum Assessment Policy Statement (CAPS) according to each subject (DoE, 1997; DoE, 2004 \& DoE, 2010). According to (Pinnock \& Hodgkin, 2020), CAPS is not a new curriculum but an amendment of the National Curriculum Statement (NCS). Therefore, CAPS still follows the same process and procedure as the NCS Grades R-12 (Pinnock \& Hodgkin, 2020).

Cross-fertilisation is necessary since educators get involved in working with other educators from other schools while equipping their skills of deriving learner activities from the syllabus. Collaboration boost educator morale. They get involved in knowledge sharing with other schools hence engaging their learners in searching for information relevant to their studies. However, educators use lessons' themes as allocated in the curriculum working in collaboration with other schools.

SMT as subject specialists, work collaboratively with the subject educators. Cross-fertilisation is important to achieve the following:

- The concept of resource sharing is learnt through the collaboration of secondary schools and the use of the concepts of advantageous strategies for collaboration ( $\mathrm{Wu}$ et al., 2004)

- The SMTs play both managerial and educator roles in preparing and organising LTSM and the resources needed by educators and learners.

- Some of the schools engaged in this collaboration are underprivileged with insufficient resources and some have the required resources. SMT and educators learn that collaboration with other schools is necessary to benefit all through the concept of knowledge sharing (Dyer \& Powell, 2001).

\section{Findings and Discussion}

The preparedness of the learners to be engaged in collaborative learning with other schools play a pivotal role. The understanding of the educators on how to involve learners in collaborative learning is also essential. Educators are engaged in different teaching programmes that can be viewed as glasses stacked on the tiers according to their degrees of importance of the structure of teaching and dialogue between the learner and the educator, and to collaborate with other schools (Moore, 1973). However, the abilities and competencies of educators play a major role in these new ways of controlling teaching and learning.

ICTs in secondary schools is growing in popularity in South Africa, and it could be useful where a lack of resources poses a significant challenge in secondary schools. Some schools have such electronic devices, whereas, on the contrary, there are those schools without electronic resources. Their collaboration with other secondary schools could afford the learners with the opportunity to use the ICT equipment from other schools. Such collaboration involves developing partnership and long-term relationships between schools to tap on the strength of each entity (Kezar \& Lester, 2009). It also involved a refined plan of delivery, effective 
Dhlamini, J. P. \& Molaodi, V. T. Cross-fertilization in Teaching and Learning between Institutions after COVID-19 Shutdown: A Collaborative Effort

development process, efficient communication, accountability and evaluation of the teaching and learning programme.

The researchers discovered that secondary schools that lack technological resources for teaching and learning find it difficult to perform academically. Such schools need to share knowledge with other schools. However, the lack of resources makes it difficult for them to access information. Findings from this study show that knowledge transfer is important in order to improve educational practices (Huberman, 1983; Love, 1985). It has been discovered that it will assist the schools to share the information with other schools, especially those who lack teaching and learning resources. Such mishaps occur in schools that are categorised in quintiles I and 2 most frequently. The knowledge transfer process in education assists in increasing the use of research results by potential users to improve learning and teaching and curriculum delivery in schools.

Another finding was that the objectives of implementing the present school curriculum which is Curriculum Assessment Policy Statement (CAPS), will be better achieved through collaboration to support teachers and learners and foster a great sense of self-worth and professionalism in the schools. Collaboration also enables teachers to develop confidence in themselves and be more effective in their obligation if educators are engaged in different teaching programmes where they recognised the structure of teaching and dialogue between them as educators and learners, as advocated by Moore (1973).

Researchers have realised that through the use of ICTs, schools could learn from the collaboration with other schools, which will help them prepare the learners to cope with the demands of tertiary institutions as this would even bring improvement to the matric result of the learners. Such projects are likely to motivate educators to specialise in different fields which are related to school subjects. The use of ICT by the educators and the learners with the teams' assistance formulated among schools could bring success. Each participant would realise the important role he/she could play helping others who do not have access to computers and other ICT material during their optional time and on the other hand, the concept of knowledge sharing, knowledge transfer, and resource sharing (Daniel, et al. 2002; Wu et al. 2004; Dyer \& Powell, 2001).

\section{Recommendations}

The researchers recommend that creating cross-fertilization between secondary schools through advantageous strategies for collaboration, knowledge sharing and knowledge transfer between schools is vital to improving teaching and learning (Dyer \& Powell, 2001). When drawing on the concept of ASC, Wu et al.'s (2004) show that the availability of teaching and learning resources is one of the effective strategies that can be achieved through collaboration.

Although debates about implementing the best strategies to bridge the existing gaps in teaching and learning within the privileged and marginalised institutions in South Africa have been ongoing even before the outbreak of COVID-19, it is thus recommended that infusing working together among schools can help the situation which the existing differences in secondary schools has exacerbated. In addition, there was an increasing concern that the reopening of schools after lockdown would also exacerbate the situation by evoking inequalities 
Dhlamini, J. P. \& Molaodi, V. T. Cross-fertilization in Teaching and Learning between Institutions after COVID-19 Shutdown: A Collaborative Effort

amongst the schools. Hence when secondary schools work together, it will help the disadvantaged to benefit from those schools that are better resourced.

The differences in funding of schools need to be in accordance with the needs of the individual school. It is recommended that schools should be equally funded or schools, especially schools in quintiles 1 and 2. If the funds that the DoE provides are insufficient, officials should consider collaboration of such schools as the best option. Where there are schools situated in rural areas and some townships with limited resources that limit online or blended learning, in order to bridge the gap between schools with sufficient resources and schools that lack resources, collaboration between secondary schools, partnerships between institutions through crossfertilisation is recommended.

School leaders, as key players of institutions, should work towards building rapport so that some school members will not feel marginalised and not get involved. Since collaboration requires the participation of all stakeholders, school principals need appropriate professional development to assist in facilitating collaboration between schools.

\section{Conclusion}

Collaboration could bridge the gaps between secondary schools since teachers would no longer be working in isolation but collaborating on teaching. This collaboration provides teachers with the opportunity to discuss strategies on learning styles, teaching and assessment. Through collaboration, there could be a development of knowledge sharing and partnerships between secondary schools. It could be concluded that knowledge sharing and knowledge transfer means the process of transforming and sharing information and skills which could be achieved through creating time, developing a sharing culture, and creating mutual relationships between schools.

The meaning of knowledge transfer in this research was suggested as the best strategy for the process of transmitting information, skills and experiences in the best practices amongst secondary schools. This process of collaboration between the secondary schools could yield transformative results. It also could benefit the learners in the schools on their learning process and integrated the information, and the knowledge gained.

\section{References}

Akinyemi, A. F., Rembe, S., Shumba, J., \& Adewumi, T. M. (2019). Collaboration and mutual support as processes established by communities of practice to improve continuing professional teachers' development in high schools. Cogent Education, 6(1), 1685446.

Bernshausen, D. \& Mcmahan, S. (2011). Innovative models for effective collaboration between universities and community colleges: Teacher concern in the PDS partnership change process. PDS Partners, 6(3), 653-664.

Daniel, H.Z., Hempel, D.J., \& Srinivasan, N. (2002). A model of value assessment in collaborative program. Industrial Marketing Management, 31, 653-664.

Department of Education [DoE]. (1997). Curriculum 2005: Lifelong learning for the $21^{\text {st }}$ century. Pretoria: Government Printers.

Department of Education [DoE]. (2004). Kadar Asmal speech on World Book Day on the 23rd April 2003. Pretoria: Government Printers. 
Dhlamini, J. P. \& Molaodi, V. T. Cross-fertilization in Teaching and Learning between Institutions after COVID-19 Shutdown: A Collaborative Effort

Department of Education [DoE]. (2010). South African Government Information Basic Education Policy and curriculum development. Pretoria: Government Printers.

Department of Education [DoE]. (2012). Department of Basic Education Annual Report 2011/2012. Pretoria: Government Printers.

Department of Basic Education (2016). South African Schools Act (84/1996) National Norms and Standards for School Funding (NNSSF). Pretoria: Government Printers

du Plessis, P. (2020). Implications of COVID-19 on the management of school financial resources in quintile 5 public schools. South African Journal of Education, 4O(4).

Dyer, J.H., \& Powell, B.C. (2001). Determinants of success in ATP-funded R\&D joint ventures: A preliminary analysis based on 18 automobile manufacturing projects. January 2001. Available https://citeseerx.ist.psu.edu/viewdoc/download?doi=10.1.1.210.3315\&rep=rep1\&typ $\underline{\mathrm{e}=\mathrm{pdf}}$

Habib, A. (2016). Transcending the past and Reimagining the Future of the South African University. Journal of Southern African Studies. 42(1) 1-14.

Havelock, R.G. (1973). Planning for innovation through dissemination and utilisation of knowledge. University of Michigan - Ann Arbor, Center of Research on Unitisation of Science Knowledge.

Heath, R. (2005). Developing partnerships between public schools and higher education. Presentation at the Annual Conference of the South Carolina and North Carolina by Professors of Middle Level Education. Charleston, South Carolina.

Heath, R., \& Johnson-Taylor, C. (2006). Developing partnership. Presentation of the older English consortium annual assistant principals' conference. Chester.

Huberman, M.A. (1983). Improving social practice through the utilisation of university-based knowledge. Higher Education, 12, 257-272

Hutchings, K. \& Michailova, S. (2003). Facilitating knowledge sharing in Russia and Chinese subsidiaries: The importance of groups and personal networks. Available at https://research-api.cbs.dk/ws/files/59101873/7316.pdf

Kezar, A.J. \& Lester, J. (2009). Organising higher education for collaboration: A guide for campus leaders. Francisco: Jossey-Bass.

Law, C.C.H., \& Ngai, E.W.T. (2008). An empirical study of the effects of knowledge sharing and learning behaviours on firm performance. Expect Systems with Applications, 34(4), 4249.

Love, J.M. (1985). Knowledge transfer and utilisation in education. Review of Research in Education, 12, 337-386

Moore, M.G. (1973). Towards a theory of independent learning and teaching. Journal of Higher Education, 44, 661-679.

Moore, M.G. (1973). Learner autonomy: The second dimension of independent learning. Convergence, 5(2), 76-88.

Nage-Sibande, B., \& van Vollenhoven, W.J. (2012). ODL answer to access to tertiary education in Southern Africa. Progressio, 34 (2), 33-47.

National Education Evaluation and Development Unit (NEEDU). (2013). National report 2012: Summary report. Pretoria: Government Printers. 
Dhlamini, J. P. \& Molaodi, V. T. Cross-fertilization in Teaching and Learning between Institutions after COVID-19 Shutdown: A Collaborative Effort

Pinnock, H. \& Hodgkin, M. (2010). Education access for all. Forced migration Review, 35 (2) 1416.

Rismark, M., \& Solvberg, A. M. (2011). Knowledge sharing in schools: A key to developing professional learning communities. World Journal of Education, 1(2), 150-160.

Walkington, NJ. \& Seguin, B. 2020. Multi-component Multiphase Porous Flow. Archive for Rational Mechanics and Analysis, 235(3) 2171-2196.

Waters, S., \& Hensley, M. (2020). Measuring rural P-12 teachers' attitudes, perceptions, and utilizations of social media. Research in Social Sciences and Technology, 5(3), 25-54.

Williams, T. K., McIntosh, R. W., \& Russell, W. B. (2021). Equity in distance education during COVID-19. Research in Social Sciences and Technology, 6(1), 1-24.

Wu, T. Wu, R.T.Y. Lin, C. \& Tseng, H. (2004). A study of the advantageous strategy construction for collaboration between small and medium enterprises and higher technological and vocational institutions by Porter's Diamond theory. Republic of China. December 2004. 